\title{
GEOGRAFIA ECONÔMICA E O ESTUDO DA INDÚSTRIA E DA INOVAÇÃO NA ATUALIDADE ${ }^{1}$
}

\author{
Diana dos Reis Pereira Carvalho \\ Fernando Luiz Araújo Sobrinho ${ }^{3}$
}

Resumo: Após 1970, com a intensificação dos processos de globalização e da Terceira Revolução Industrial, renovam-se os debates teórico-metodológicos na Geografia relativos, sobretudo, aos desdobramentos das inovações sobre as perspectivas de desenvolvimento regional e a distribuição ou concentração de atividades inovadoras no espaço geográfico. Este artigo objetiva levantar e discutir contribuições atuais sobre os temas da indústria e da inovação na área da Geografia Econômica. Realizou-se levantamento, seleção e revisão de estudos de autores reconhecidos no Brasil, configurando o estado da arte nesse campo. Discute-se abordagens gerais; sistemas territoriais inovadores e tecnopolos; classificação, definição e elementos da inovação localizada (Georges Benko); inovação e tecnologia no espaço geográfico (André Fischer); tipologias de Distritos industriais Dls (Ann Markusen). Portanto, os estudos consolidados da indústria consideram meios inovadores e Dls para promoção econômica, quando novo paradigma reformula e define temas, conceitos e metodologias para explicar a realidade geográfica dos países e regiões.

Palavras-chave: Geografia; CT\&l; desenvolvimento regional; ambientes de inovação.

\section{ECONOMIC GEOGRAPHY AND THE STUDY OF INDUSTRY AND INNOVATION}

\begin{abstract}
After 1970, with the intensification of the process of globalization and the Third Industrial Revolution, theoretical and methodological debates in Geography were renewed, especially about the impacts of innovations on the prospects of regional development and on the distribution or concentration of innovative activities in geographical space. This article aims to raise and discuss current contributions on the topics of industry and innovation in the area of Economic Geography. A survey, selection and review of studies by recognized authors in Brazil was carried out, configuring the state of the art in this field. Discusses general approaches; innovative territorial systems and technopoles; classification, definition and elements of localized innovation (Georges Benko); innovation and technology in the geographical space (André Fischer); typologies of Industrial Districts - IDs (Ann Markusen). Therefore, the consolidated studies of the industry consider innovative means and Dls for economic promotion, when new paradigm reformulates and defines themes,
\end{abstract}

\footnotetext{
${ }^{1}$ Este artigo foi elaborado na disciplina Planejamento Regional, do Programa de Pós-Graduação em Geografia da Universidade de Brasília (UnB), ministrada pelo professor Fernando Sobrinho. Relaciona-se à pesquisa de doutorado na UnB que realiza uma "análise geográfica dos ambientes de inovação brasileiros: discussão do Programa Nacional de Incubadoras de Empresas e Parques Tecnológicos", sob orientação do Professor Dr. Dante Flávio da Costa Reis Júnior. Este artigo é antecedido por outro que abordou a visão histórica e os temas atuais da Geografia Econômica, conforme Carvalho e Veloso Filho (2017).

${ }_{2}^{2}$ Universidade de Brasília (UnB). Departamento de Geografia. E-mail: dyanapc2009@hotmail.com

${ }^{3}$ Doutor em Geografia. Docente da Universidade de Brasília (UnB). E-mail: flasobrinho@gmail.com

Estudos Geográficos, Rio Claro, 15(1): 1-25, jan./jun. 2017 (ISSN 1678-698X)

http://www.periodicos.rc.biblioteca.unesp.br/index.php/estgeo
} 
concepts and methodologies to explain the geographical reality of different countries and regions.

Keywords: Geography; CT \& I; regional development; Innovation environments.

\section{INTRODUÇÃO}

Nas últimas décadas, transformações econômico-sociais geraram discussões e abordagens novas nas Ciências. A geografia econômica adotou tendências que serão base das interpretações dos estudos da atividade industrial (e sua espacialização). Este trabalho objetiva discutir o estudo da atividade industrial e da inovação na geografia econômica contemporânea, com base nas perspectivas consolidadas - o estado da arte desse ramo sobre o tema. A pesquisa se fundamenta em levantamento, seleção e revisão de contribuições estrangeiras reconhecidas no Brasil, como os trabalhos de Georges Benko (1996); André Fischer (Org. Firkowski; Sposito, 2008); e Ann Markusen (1995).

Busca-se realizar um painel geral destes estudos no mundo - o estado da arte da geografia econômica no que se refere às atividades da indústria e da inovação, com indicações dessas perspectivas em trabalhos realizados no Brasil, bem como as tendências mais recentes desse ramo, sem o propósito de enfatizar a discussão atual.

Este trabalho possui quatro partes: 1) O contexto socioeconômico e as abordagens gerais que influenciam os estudos da geografia econômica na contemporaneidade; 2) Os sistemas locais inovadores - teoria da localização, definição de tecnopolos, classificação de meios locais inovadores e elementos de inovação localizada na França em um estudo regional, por G. Benko; 3) A evolução da geografia econômica/industrial com ênfase nos efeitos geográficos da inovação e das novas tecnologias, por A. Fischer e 4) Tipologias de Distritos Industriais - Dls (sticky place), áreas espacialmente delimitadas e presentes em países desenvolvidos e em desenvolvimento, alternativos ao modelo marshalliano (e sua variante italiana), por A. Markusen.

Identificou-se que as transformações na economia após 1970 conduziram às interpretações nas seguintes bases: neoschumpeteriana e regulacionista, contribuições teórico-metodológicas que foram utilizadas pela Economia, Sociologia, Ciência Política e Geografia; californiana (geógrafos). A mudança de paradigma envolve: a criação de setores e espaços econômicos - indústria de alta tecnologia, serviços (metrópoles) e práticas artesanais e Pequenas e Médias Empresas (PME); a definição e implantação de estratégias e políticas como novas formas de regulação e de intervenção governamental.

A nova configuração espacial da economia contemporânea estabelece novos setores e áreas industriais de inovação em cidades e regiões (França e Cidade Científica de llê-de-France). Esses tecnopolos, sistemas produtivos locais ou meios inovadores, se localizam em regiões com pessoas muito qualificadas, próximos a universidades e centros de pesquisa, em um ambiente de negócios e serviços diversos relacionados às indústrias de alta tecnologia. Os mesmos são parte da organização espaço-econômica do sistema produtivo francês e de espaços estimuladores para implantação do regime flexível (BENKO, 1996, p. 30).

Considera-se que as perspectivas da geografia econômica/indústria são definidas pelas abordagens: descritiva (primeiras mutações), até 1950; estrutural

Estudos Geográficos, Rio Claro, 15(1): 1-25, jan./jun. 2017 (ISSN 1678—698X)

http://www.periodicos.rc.biblioteca.unesp.br/index.php/estgeo 
(grandes perturbações), por volta de 1960; política (tempo de confirmações), anos 1980 e, mais recentemente, esse ramo disciplinar aborda a concepção da inovação tecnológica (Fischer, 2008). Markusen (1995) analisa áreas de atração de investimento em um mundo globalizado apontando áreas espacialmente delimitadas. A autora apresenta três DIs alternativos aos da Terceira Itália, de pequenas firmas flexíveis, como "centro-radial; plataforma industrial satélite; e suportado pelo Estado", em economias regionais. Eles resultam da ação do governo e das multinacionais que influenciam na configuração desses Dls de médias e grandes empresas, propensos a estabelecer redes de negócios interdistritais.

Portanto, houve uma renovação da disciplina após 1970, com a emergência de um novo sistema produtivo, no momento em que a inovação é fundamental e exige novos conhecimentos. Isso contribuiu para interpretações teóricas e aplicadas na geografia por meio do estudo dos fatores de localização, concentração de atividades econômicas e áreas industriais inovadoras locais e inter-regionais, espacialmente delimitadas (DIs) e aglomerações produtivas (meios inovadores). No Brasil, as discussões da tecnologia e inovação sobressaem após 1990 nos âmbitos acadêmico e da agenda política de promoção de Arranjos Produtivos Locais - APLs e de ambientes de inovação.

\section{ABORDAGENS CONTEMPORÂNEAS NA GEOGRAFIA ECONÔMICA}

A geografia econômica passou por rupturas intelectuais no decorrer dos anos 1970, marcada por condições internas e externas vindas de outras disciplinas e condições socioeconômicas (BENKO, 2009, p. 115). Ao tratar da evolução da geografia econômica clássica - de inspiração da economia espacial - da economia política e suas alternativas, Paul Claval corrobora que o desenvolvimento desse ramo científico na atualidade combinou diversas abordagens, incluindo a perspectiva da economia da informação e da comunicação, dos distritos industriais e da economia do conhecimento (CLAVAL, 2012, p.14).

Um dos objetivos da geografia consiste em entender as configurações espaciais de fenômenos geográficos: perceber como a atividade industrial transforma o espaço terrestre pelo impacto econômico é o fundamento da geografia Industrial. As modificações após 1970, em termos econômicos, organizacionais e de conceitos se refletem no âmbito geográfico que recebem influência das abordagens supracitadas. Considerando o enfoque da inovação e das novas tecnologias, os efeitos geográficos resultaram na transformação do conteúdo da atividade industrial, na organização espacial da indústria e na estruturação dos espaços geográficos (FISCHER, 2008b, p. 23). Nesse sentido, Benko (1996, p. 24) aponta que a dimensão tecnológica tornou-se fundamental e a indústria de ponta é um dos principais motores da economia.

O mesmo autor identifica que, com a crise econômica dos anos 1970 e suas consequências nos estudos científicos, surgem novas abordagens gerais: Economia Evolucionista, em que os neoschumpeterianos tratam da mudança tecnológica e da inovação na análise do crescimento econômico; Economia dos Italianos da Terceira Itália, tratando do caráter socialmente endógeno do desenvolvimento e da organização industrial em pequenas empresas especializadas; perspectiva da geografia econômica dos californianos que se pautou, sobretudo, nas análises do

Estudos Geográficos, Rio Claro, 15(1): 1-25, jan./jun. 2017 (ISSN 1678—698X)

http://www.periodicos.rc.biblioteca.unesp.br/index.php/estgeo 
processo da divisão do trabalho e das consequências externas de aglomeração; e Escola da Regulação, originária dos economistas franceses, que buscou 0 entendimento da passagem do regime fordista para o flexível.

Os debates das geografias econômica, urbana e regional inserem os conceitos: de regimes de acumulação flexível; de teoria pós-weberiana da localização industrial; de sistemas/meios inovadores e novos espaços industriais (BENKO, op. cit., p. 124). A partir de 1980, há um retorno da análise das aglomerações produtivas, os meios inovadores, para o desenvolvimento endógeno (FISCHER, 2008a, p. 21) e dos Dls de produção pós-fordista, com a presença de grandes firmas e a ação do governo para o desenvolvimento regional (Markusen, 1995, p. 10).

A velocidade das modificações tecnológicas e a aceleração dos processos de inovação refletem na localização das atividades industriais e na organização espacial da nova geração de espaços industriais como parques de atividades, parques científicos e tecnopolos (FISCHER, 2008b, p. 49). Um formato próprio de distrito foi objeto de análise de "economistas, geógrafos e sociólogos sob o nome de tecnopólo" (BENKO, 1996, p. 96); uma perspectiva da escola francesa da regulação que enfatiza os sistemas locais inovadores, a exemplo da Cidade Científica de Paris.

Segundo Benko (1996), a natureza da paisagem econômica mudou ao longo dos anos 1970/1980 resultando, dentre outras mudanças, em três novos espaços econômicos que se agrupam em torno da noção de DI: 1) Indústrias de alta tecnologia (novos complexos de produção), como o Silicon Valley, o Orange County e a Route 128, em regiões da Europa e dos EUA; 2) Metrópoles, que oferecem concentrações em serviços a empresas e 3) Atividades artesanais e Pequenas e Médias Empresas - PMEs (Terceira Itália). Assim, o autor identifica aglomerações tecnológicas, como a região do Vale do Silício; DIs da Terceira Itália; e as grandes metrópoles, fundamentadas em Alfred Marshall, reinterpretadas através da Teoria dos Custos de Transação ou das Teorias Evolucionistas.

Conforme Benko (2009, p. 117), o trabalho dos italianos sobre a Terceira Itália permitiu reintroduzir o conceito de DI de Alfred Marshall. No contexto regulacionista, $\mathrm{M}$. Piore e $\mathrm{C}$. Sabel trataram do sucesso dos Dls como um cenário típico de uma tendência mais ampla. Na França, são introduzidas pesquisas sobre sistemas industriais localizados pela equipe de Grenoble, liderada por C. Courlet e B. Pecqueur. O grupo liderado por J. P. Gilly tratou da industrialização e da inovação no território. Os geógrafos econômicos da Escola Californiana, sobretudo, A. J. Scott, M. Storper e R. Walker, identificando o crescimento de Los Angeles, trataram inicialmente de metrópoles e, depois, de patchworks de Dls.

Outra abordagem, desenvolvida pela equipe europeia sobre milieu inovador - Associação Philippe Aydalot, considerou o próprio território como "meio inovador". Já os evolucionistas, consideraram o território como propício à inovação. Os trabalhos recentes se aproximam cada vez mais da ênfase e difusão da inovação. Os regulacionistas consideram as maneiras de direção entre as empresas, o perfil de vinculação capital-trabalho que sobressai no território, as políticas de promoção local, dentre outras.

Markusen (1995, p. 11) também identifica que M. Piore e C. Sabel, ao tratarem da evolução da noção de especialização flexível e de distritos industriais, pesquisaram exaustivamente a experiência da Terceira Itália. A autora ainda mostra que outras proposições resultaram fundamentais como: S. Christopherson e W. Storper sobre a indústria do cinema em Los Angeles; A. Scott e A. Paul sobre a Estudos Geográficos, Rio Claro, 15(1): 1-25, jan./jun. 2017 (ISSN 1678—698X) http://www.periodicos.rc.biblioteca.unesp.br/index.php/estgeo 
experiência do Condado de Orange; e as pesquisas de A. Saxenian sobre o Silicon Valley. Isso gerou grande debate sobre a aplicação e precisão das formulações sobre Dls, renovando a produção da disciplina.

Os modelos modernos de DIs têm influência nas diversas perspectivas geográficas (CLAVAL, 2012, p. 15) para além dos Dls de pequenas firmas, de desenvolvimento endógeno (MARKUSEN, 1995, p. 10). Juntamente com pequenas empresas inovadoras associadas em arranjos cooperativos e especialização flexível, como os DIs da Terceira Itália, coexistem os Dls centro-radial, plataforma satélite, ancorado pelo Estado - como indicação de atividade econômica de exportação e especialização determinada; que mostram a atuação dos governos e de corporações multinacionais na sua formatação.

Portanto, entende-se que as pesquisas geográficas foram influenciadas pelas mudanças econômico-sociais e abordagens gerais que alteraram e ampliaram as pesquisas após 1970/80. Novos paradigmas reformulam e definem temas e conceitos novos para explicar a realidade geográfica dos países e regiões e contribuir com o planejamento. Nas discussões sobre a geografia econômica, temas como áreas industriais (para pequenas e grandes empresas), inovação e aspectos mais gerais como a globalização, o conhecimento e a informação - como processo fundamental na sociedade atual e a interpretação do modelo produtivo flexível - são parte dos trabalhos atuais dos geógrafos.

A seguir, utiliza-se as interpretações de Georges Benko; André Fischer (textos organizados por Firkowski; Sposito, 2008); e Ann Markusen. Georges Benko, numa perspectiva regulacionista, trata de um novo modelo de desenvolvimento e da nova dinâmica espacial, com foco nos sistemas de inovação (classificação), conceituando tecnopolos e aplicando à França e à região de llê-de-France (Cidade Científica); André Fischer (2008a) apresenta as perspectivas da disciplina e denomina tempos de confirmação às modificações que se refletem na geografia Industrial na contemporaneidade, apontando os efeitos geográficos da inovação e novas tecnologias; e Ann Markusen que, além do DI marshalliano (e sua variante italiana) de especialização flexível, propõe três tipos de Dls no âmbito da economia regional, pela ação dos governos e das multinacionais.

\section{GEOGRAFIA ECONÔMICA E NOVA ORGANIZAÇÃO ESPACIAL/INDUSTRIAL: MEIOS LOCAIS INOVADORES}

Georges Benko ${ }^{4}$ é referência nos âmbitos da geografia econômica e da economia regional em vários países, inclusive no Brasil. Possui pesquisas de

\footnotetext{
${ }^{4}$ Georges Benko (1953-2009) era geógrafo e arquiteto. Ele possuía doutorado em geografia pela École dês Hautes Études em Sciences Sociales de Paris (1982). Foi nesta cidade onde desempenhou maior parte de sua atividade docente sendo, por vários anos, professor da escola de Arquitetura (París-Villemin), além dos departamentos de Geografia das Universidades de Paris IV, Paris XII e, finalmente, Paris I onde trabalhava desde 1992. Era pesquisador do CRIA (criado por André Fischer). Foi fundador e editor da revista "Géograhie, Économie Societé" e presidente do Centro de Estudos e Pesquisas Urbanas e Regionais, desde sua fundação. Participou das atividades da Associação de Ciência Regional em língua Francesca colaborando como membro do Conselho Científico de Investigações Regionais e em atividades do grupo de geografia econômica da Associação de Geógrafos Espanhóis (MÉNDEZ, 2009, s.p.). Foi convidado a ministrar conferências e cursos no Brasil, na Universidade de São Paulo (USP).
}

Estudos Geográficos, Rio Claro, 15(1): 1-25, jan./jun. 2017 (ISSN 1678—698X)

http://www.periodicos.rc.biblioteca.unesp.br/index.php/estgeo 
variado conteúdo conceitual ao longo da carreira acadêmica ${ }^{5}$. A obra selecionada é "economia, espaço e globalização", (1996), que traz reflexões teóricas e práticas para um estudo regional (França e a Cidade Científica de llê-de-France). O trabalho de $\mathrm{G}$. Benko parte do debate das mudanças do sistema produtivo, inserindo-se na abordagem regulacionista ${ }^{7}$.

Após 1970, as mutações econômicas trouxeram elementos novos para as discussões e pesquisas sobre a industrialização contemporânea. Houve a reestruturação da indústria, aumento das atividades de serviço e a produção de alta tecnologia, que transformou a organização territorial.

As explicações ou interpretações dos fatos econômicos do pós-guerra forneceram uma leitura das mudanças em curso na economia, surgindo noções de pós-fordismo e produção e acumulação flexível, utilizadas nas pesquisas de estudo de localização industrial e em análises mais gerais sobre a condição pós-moderna em disciplinas que vão da Sociologia e da Economia, às Relações Industriais. Essas noções foram muito empregadas na França e nos países ocidentais nos debates sobre a política industrial (BENKO, 1996, p. 34).

A dinâmica dos novos espaços econômicos concentra-se nas transformações das atividades econômicas e em seu comportamento geográfico, que se liga à teoria da localização industrial, um dos principais objetos de estudo da geografia econômica, que Benko (1996, p. 14) denomina pós-weberiana. Por isso, investiga-se a atividade industrial e a sua difusão no espaço urbano bem como as tendências que surgem no tema.

Considerando que as primeiras teorias fundamentaram-se nos fatores clássicos de menores custos, a abordagem atual considera as características dos lugares e dos meios inovadores como o caráter dos complexos territoriais de inovação, interdependente de variáveis como recursos locais, know-how, qualificação; e os aspectos que fazem certos lugares serem mais inovadores que outros. Portanto, o propósito da teoria da localização é explicar a "organização espacial das empresas, identificar as variáveis que determinam a localização,

\footnotetext{
5 Foi editor de "A dinâmica espacial da economia contemporânea" (1990). "As regiões que ganham" (1992); e "A riqueza das regiões. A nova geografia socioeconômica" (2000) foram coeditados com Alain Lipietz; "Mudança industrial e o desenvolvimento regional" (1991), coeditado com Mick Dunford e "teoria social e espaço" (1997), coeditado com U. Strohmayer. Além de trabalhos individuais como o artigo "desenvolvimento sustentável e distrito industrial" (2001), publicado pela revista brasileira RA'EGA; e os livros "Geografia dos tecnopolos" (1991); e "Economia, espaço e globalização" (1996) - (MÉNDEZ, op. cit.).
}

${ }^{6}$ A obra possui três partes: I) Economias e territórios em mutação - trata da passagem de regime de acumulação fordista para um pós-fordista, flexível; e o deslocamento geográfico das atividades econômicas vincula-se à concepção da teoria da localização industrial; II) O sistema produtivo contemporâneo - faz reflexão sobre a lógica do sistema inteiro e a localização das atividades de ponta bem como os novos espaços industriais; e III) Fisionomias da França - análises aplicadas. Com o intuito de identificar um estudo prático da indústria na geografia, demonstra-se que o autor, a partir da discussão teórica, no contexto contemporâneo (sistema produtivo pós-fordista), trata da Cidade Científica (parte III) em que descreve os aspectos humanos, o potencial econômico, de formação e de pesquisa e os parques industriais existentes.

${ }^{7}$ A Teoria da Regulação é uma abordagem instituída pela escola francesa da economia política, na década de 1970, a partir da especificidade da crise fordiana. A análise parte da instabilidade de acumulação fordista considerando que o capitalismo entra numa fase de acumulação flexível. Tem como marco o trabalho de Michel Aglieta (1976) e os expoentes R. Boyer e A. Lipietz. Durante os anos 1980, disseminou-se a outras disciplinas como geografia e relações industriais e a outros países, como os anglo-saxões. Surgiu como uma reforma do enfoque estruturalista oferecendo nova leitura da história econômica. Um dos constitutivos da escola da regulação tratou de integrar um motor endógeno à expansão do capitalismo. Surge novo modelo de desenvolvimento/pós-fordista com reestruturação espacial de toda sociedade, redefinição da natureza dos espaços e papel das redes (Benko, 1996, p. 91;246).

Estudos Geográficos, Rio Claro, 15(1): 1-25, jan./jun. 2017 (ISSN 1678-698X)

http://www.periodicos.rc.biblioteca.unesp.br/index.php/estgeo 
oferecer soluções analíticas, trazer respostas ao crescimento espacial das empresas e à influência do meio ambiente" (BENKO, 1996, p. 132).

A relevância e o arranjo dos fatores de localização não são semelhantes para todos os ramos de indústria ou para o tamanho dos empreendimentos. Alguns fatores (variáveis) que podem ser expostos para estudos baseados nos complexos industriais de alta tecnologia são:

1) A força de trabalho (capital humano);

2) Universidades e institutos de pesquisa;

3) o atrativo da paisagem;

4) a infraestrutura de transportes;

5) os serviços e o clima político e dos negócios;

6) as economias de aglomeração (BENKO, op. cit., p. 133).

Além dos fatores citados, a teoria do ciclo do produto é um dos elementos mais discutidos na teoria da localização de ponta. Essa teoria alia a localização à organização da produção (um movimento que vai da concentração e da centralização à descentralização e à dispersão da produção). A terceira tendência da localização industrial está ligada às condições geográficas (econômicas, sociais, físicas) da produção. Ela trata das questões da inovação tecnológica nos meios regionais. Esse pensamento propõe o papel determinante desempenhado pelos meios locais como incubadores de inovação, definido como:

Conjunto territorializado no qual as redes inovadoras se desenvolvem pela aprendizagem que seus atores fazem de transações multilaterais geradoras de externalidades inerentes à inovação e por convergência das aprendizagens com formas cada vez mais competitivas de criação tecnológica (Perrin, 1989 apud Benko, 1996, p. 140).

Conforme Benko (op. cit., p. 140), as aglomerações são consideradas espaços propícios à inovação e novos meios inovadores que se tornaram complexos territoriais de inovação, termo utilizado por Walter Stöhr (1986). Os tecnopolos surgem como sistemas produtivos locais inovadores, uma forma específica de DI, tornando-se tema de vários ramos científicos. Neles se empregam formas produtivas alternativas justapostas ao fordismo, constituindo o núcleo da organização espaçoeconômica do sistema produtivo francês. Os tecnopolos constituem "pontos de ancoragem das novas articulações entre economias nacionais e internacionais" defendendo que "poderão tornar-se estimuladores na implantação do regime de acumulação flexível" (BENKO, 1996, p. 156). Portanto, trata dos sistemas de inovação locais existentes na França.

Benko (1996, p. 153) aponta que o tecnopolo é um centro marcado pelas atividades industriais de alta tecnologia, sendo fundamental na transferência de tecnologia; integrando-se à definição de desenvolvimento polarizado dos anos 1950/60 é um "aglomerado de empresas inovadoras, dinâmicas, motrizes e em que o investimento nas empresas mais rentáveis (em renda per capita e emprego) tem efeitos relevantes em toda a economia regional". O mesmo é utilizado como instrumento de desenvolvimento econômico e de urbanização, como se observa: 
Geografia econômica e o estudo da indústria...

Os tecnopolos são utilizados por cidades cujas estratégias de desenvolvimento econômico se apoiam na valorização de seu potencial universitário e de pesquisa, esperando que este provoque uma industrialização nova por iniciativas de empresas de alta tecnologia, criadas localmente ou atraídas;

Operacionalmente é um agrupamento de organizações de pesquisas e de negócios que se ligam ao desenvolvimento científico, englobando um processo de conjunto, da etapa do laboratório à da fabricação e da comercialização do produto;

Fisicamente é um conjunto de empresas (sobretudo, pequenas e médias) - escritórios, laboratórios e unidades de fabricação que são estruturadas num ambiente de qualidade;

No nível de localização, geralmente se situa num sistema relacional fechado, com universidades e institutos de pesquisa técnica, públicos e privados;

Em termos práticos é identificado o papel da produção imobiliária, que realiza e vende o tecnopolo conforme interesse;

Em termos de urbanização, o tecnopolo se constitui como processo complexo de territorialização-relocalização no seio das estratégias das firmas dominantes, demonstrando ancoragem e integração da variável espacial nas estratégias elaboradas pelas coletividades locais (BENKO, 1996, p. 153).

Conforme Benko (1996), um tecnopolo pode ser conhecido a partir de alguns indicadores. O uso desses dados estatísticos possibilita dizer se é um tecnopolo/polo tecnológico:

Proporção de empregados cientistas e técnicos no emprego total, o volume dos gastos com a pesquisa e o desenvolvimento, o nível de aperfeiçoamento do produto fabricado no ramo industrial e seu lugar na nomenclatura, a taxa de crescimento de empregos no interior do setor (BENKO, 1996, p. 155).

A função mínima de um tecnopolo é acolher empresas, sendo uma "zona de urbanização que induz estratégias de promoção orientada para a implantação de entidades tecnológicas". Portanto, no âmbito regional, os tecnopolos são instrumentos favoráveis ao desenvolvimento de regiões, espaços propícios às indústrias de alta tecnologia, high tech ou de tecnologia de ponta que deve oferecer serviços às empresas (BENKO, 1996, p. 155).

O fim do século é o denominado pós-industrial, pós-fordista, pós-nacional e/ou pós-moderno e, no contexto da organização econômica do território, a dualidade global-local torna-se um dos centros dos debates nas ciências e, sobretudo, na geografia. A discussão do desenvolvimento é fundamental em economia regional e urbana bem como na geografia econômica. Benko (op. cit., p. 68), por exemplo, propõe tratar do desenvolvimento regional pelo viés da reaglomeração visível da produção e pela globalização dos fluxos econômicos. Para discutir a globalização econômica, examina três elementos maiores: industrialização, urbanização e sistemas locais inovadores - onde propõe uma classificação.

Segundo Benko (1996, p. 75), o pensamento econômico apresenta a globalização pelo mercado e pela globalização nacional, não integráveis. Ele propõe superar essa dicotomia e dar uma explicação através de enfoque dinâmico. Inicia

Estudos Geográficos, Rio Claro, 15(1): 1-25, jan./jun. 2017 (ISSN 1678—698X)

http://www.periodicos.rc.biblioteca.unesp.br/index.php/estgeo 
apresentando o conceito de globalidade dinâmica que serviu de referência para analisar a abertura dos sistemas locais para seu milieu. Ele considera primeiro o processo de globalização que procede dos sistemas locais inovadores que se desdobram, por sua vez, sobre o seu hinterland, transformando-o e criando um novo sistema integrado, de tipo regional. O impacto da Revolução Industrial sobre os contextos locais se deveu à conjuntura dos ambientes que o compõem.

Segundo Benko (op. cit., p. 76), as capacidades dinâmicas dos sistemas locais com ambientes inovadores os projetam, espontaneamente, para o exterior através da intensificação das trocas com outros territórios; e do desdobramento em seu hinterland direto, que encontra o meio de retomar eficazmente seu desenvolvimento. Ao estender o próprio sistema de organização a espaços novos e diferentes, o ambiente local inventa e utiliza novas estruturas econômicas e territoriais. Assim, determinadas economias urbanas (como Veneza e seu hinterland rural; e Lyon, cidade mercantil, manufatureira e financeira, núcleo da transformação econômica de seu hinterland) transformaram-se em economia regional. O milieu local inovador estimulado pelas técnicas industriais conduz a uma globalização territorial regional. Devido às infraestruturas de mercado, as atividades manufatureiras, impulsionadas pelas metrópoles, desenvolveram-se nas regiões.

Assim, Benko (1996) afirma que "a globalização da economia metropolitana na economia regional caminha com o estabelecimento de uma nova organização territorial que é efeito e causa do desenvolvimento geral". Ela se caracteriza pela emergência de uma territorialidade regional que funda dois sistemas organizacionais: sistemas locais e regiões.

O sistema região promove, entre os sistemas locais, relações dinâmicas que somam criatividade global e, assim, a capacidade dos sistemas constituintes. No decorrer do tempo, o formato dessa rede evolui de uma configuração urbana para uma configuração pluripolar na qual os principais sistemas locais compartilham as funções superiores regionais, especialmente tecnopolitanas. Ao fim dessa globalização econômica surge um meio inovador regional; que não substitui os meios locais, nem é a soma destes. Nesse sentido, os atores importantes para estratégias de desenvolvimento são as empresas, Estados e os milieu locais. Benko (1996, p. 79) afirma que as empresas e os Estados estabeleceram políticas que modificaram as formas de globalização econômica e argumenta que "os contextos locais de meios inovadores ou dinâmicos assumiram 0 controle dessas transformações fazendo-as servir ao seu desenvolvimento".

A partir da base teórica da regulação e das mudanças que caracterizam a Revolução Industrial, G. Benko (1996, p. 84) propõe uma classificação de quatro sistemas territoriais em meios inovadores: 1) sistemas territoriais dinâmicos - que controlam as forças micro e macro da globalização e que as colocaram a emprego de seu próprio desenvolvimento; 2) contextos locais de meios que se não inovadores, são dinâmicos - eles conseguiram organizar-se para tirar proveito das oportunidades e que conheceram, por isso, desenvolvimento importante; 3) contextos locais cujos meios não são inovadores, nem dinâmicos - pseudo sistemas territoriais, assim qualificados, pois não possuem dinâmica autógena; seus milieu são desestruturados e padecem de políticas de multinacionais e dos Estados1 e 4) sistema de dinâmica mantida de maneira exógena - o de Paris e da llê-de-France, da estrutura espaço-econômica que resulta da importância e das vantagens elevadas que um sistema político e econômico centralizado imputa à sua capital.

Estudos Geográficos, Rio Claro, 15(1): 1-25, jan./jun. 2017 (ISSN 1678—698X)

http://www.periodicos.rc.biblioteca.unesp.br/index.php/estgeo 
Após as classificações propostas, Benko (1996, p. 205) realiza um trabalho característico da indústria, com foco nos meios inovadores regionais. Seu trabalho aponta a concentração de atividades econômicas, os movimentos de mão de obra, os padrões de distribuição industrial, as relações da indústria com a urbanização e a política governamental de desenvolvimento, no contexto da inovação.

Como estudo de geografia industrial, Benko (1996, p.199) faz uma avaliação da França (22 regiões) e de algumas cidades ou territórios urbanos, a partir de três aspectos maiores: metropolização; industrialização; e planejamento. Analisa regionalmente a França, llê-de-France e a Cidade Científica (llê-de-France-Sud) iniciando com "a dinâmica espacial na França", e o modelo de desenvolvimento, após a Segunda Guerra. Benko (1996, p. 185) mostra a França fordista do pósguerra, considerando a especialização regional dos diferentes tipos de trabalho e indústria de equipamento:

a) regiões de tipo I, polos direcionais financeiros e tecnológicos; b) regiões do tipo II, de fabricações qualificadas (o que supõe um passado industrial, como o Norte-Pas-de-Calais); c) regiões do tipo III, que apresentam reservas de mão de obra que se pode considerar como não qualificadas e de baixo valor de reprodução, pois produzidas pela dissolução de outros modos ou pelo declínio de indústrias em obsolescência que correspondem a um estágio anterior da divisão do trabalho; onde se desenvolvem as atividades de montagem (operários especializados); d) regiões do tipo IV, onde o êxodo rural já havia sido levado tão longe que nenhuma industrialização era possível - regiões não integradas, devido à menor polarização fordista (BENKO, 1996, p. 186).

A caracterização das regiões é realizada a partir do tipo de predomínio de setor econômico e da qualificação dos profissionais. Por isso, Benko (1996, p. 186) qualifica as regiões supracitadas em: metrópole de comando e meio; velhas regiões industriais; antigas regiões agrícolas; e regiões pós-industriais (terciárias).

a) A "metrópole de comando" e meio é a região do tipo I, île-de-France (região de Paris) e Ródano-Alpes (região de Lyon); b) As velhas regiões industriais, regiões do tipo II, especializada na fabricação industrial - Ródano-Alpes, Norte-Pasde-Calais e Alsácia cuja estrutura das atividades primária/secundária/terciária são semelhantes; c) As antigas regiões agrícolas, tipo III são Centro e Bretanha, especializadas na montagem sem qualificação; poucos engenheiros e muitos OEs. O primeiro já é muito industrializado, típico da desconcentração industrial da região parisiense. Sobre a estrutura produtiva nessas indústrias há o menor número de engenheiros e o maior de Operários especializados não qualificados (OEs); d) As regiões ensolaradas ou pós-industriais, tipo IV, são classificadas pelo peso da agricultura e fraca industrialização que marcam por sua densidade e por sua qualidade terciária, equilibrada e superqualificada - regiões mediterrâneas.

Para Benko (1996, p. 190), com a estrutura espacial induzida pela crise fordista, a análise regional do espaço francês após 1980 é ilustrada por meio de hexágonos. O primeiro eixo de análise opõe sempre a França do Nordeste à França do Sudoeste; o segundo eixo opõe profundamente a Île-de-France aos outros (Parisprovíncia); o terceiro eixo opõe as regiões fordistas a todas as outras.

Sobre a Cidade Científica (centro em Orsay, Essone), Benko (1996, p. 206), inicia afirmando que é um dos mais importantes espaços de tecnologia. Ela tem dois Estudos Geográficos, Rio Claro, 15(1): 1-25, jan./jun. 2017 (ISSN 1678-698X) http://www.periodicos.rc.biblioteca.unesp.br/index.php/estgeo 
significados, conforme Benko (1996, p. 206): é um território na Île-de-France e onde a produção sob formas novas encontra fertilidade, constituindo uma área pósfordista; e de outro, é uma organização administrativa que orienta a evolução da zona. A criação desse meio inovador objetivou o desenvolvimento da indústria de alta tecnologia. Benko (1996, p. 205) caracteriza a região a partir da história territorial e econômica, mostrando que na economia nacional, a região Sul de Paris desempenhou papel preponderante desde o século XVIII. Ele descreve a dinâmica espacial da Cidade Científica a partir dos dados humanos: população, formação, pesquisa; do potencial econômico; dos parques industriais existentes; e ação de políticas de inovação.

Identifica a superfície territorial, a quantidade de comunas e de habitantes, mostrando que a Cidade Científica recobre o território de St.-Quentin-em-Yvelines a Évery, espaço que se encontra na "segunda coroa" do subúrbio parisiense. Sua fronteira ao norte é a "pequena coroa", que conheceu desenvolvimento rápido no princípio do século, baseado nas indústrias de produção em massa e uma urbanização muito densa. A concentração industrial e urbana provocou efeitos externos negativos no ambiente local. Essa situação favoreceu o nascimento da Cidade Científica que coincide com o planejamento urbano de 1960 e expandiu atividades industriais, devido às imagens positiva de dinâmica, científica e competitiva.

Por fim, Benko (1996, p. 206) aponta a inovação localizada no território francês, a partir da criação de áreas implantadas como os tecnopolos/meios inovadores e da estrutura institucional - política de urbanização, criação de agências regionais. A Agence Nationale pour La Valorisation de la Recherche (Anvar), os Centres Régionaux d'Innovation de Transfert de Technologie (CRITTs) e a "Association Cité Scientifique" (Universidade de Orsay é um membro fundador) constituem um quadro que facilita os contatos entre os diferentes interventores: políticas locais, política regional, empresas privadas, laboratórios e universidades.

\section{PERSPECTIVAS DA GEOGRAFIA DA INDÚSTRIA CONTEMPORÂNEA E OS ASPECTOS DA INOVAÇÃO}

Sobre a geografia industrial contemporânea, foram selecionados textos de André Fischer ${ }^{8}$ (parte I), organizado em uma obra de três partes ${ }^{9}$ por Firkowski e

\footnotetext{
${ }^{8}$ O geógrafo André Fischer (1935-) é professor emérito da Universidade de Paris. Ele foi criador e coordenador do Centre Recherches sur L'Industrie et L'Aménagement (CRIA), importante na formação de quadros especializados de geografia. Desde 1970, tem grande produção científica nas áreas da Geografia Econômica; Geografia Industrial; Geografia Regional; Ordenamento do território; e Transportes. Estudou a dimensão espacial da atividade industrial no contexto das mutações e suas consequências no território.
}

${ }^{9}$ É uma obra de Geografia Industrial de diferentes formas conceituais e fases de sua carreira acadêmica (19631996), com temas agrupados em três partes, com 11 textos que tratam dos aspectos da indústria: 1) Indústria (possui cinco artigos); 2) Ordenamento do território (possui quatro textos em que trata da ação do planejador com suas problemáticas, preocupações e métodos de intervenção, e as possibilidades de ordenamento; e estabelece diferença entre planificação e aménagement); e 3) Transportes (possui dois textos, com o primeiro tratando da relação clássica dos transportes e da localização industrial; e o segundo da classificação dos portos marítimos). A atividade industrial em suas relações com o território é o tema principal de Fischer (BREITBACH, 2009). Na primeira parte do livro, interesse deste trabalho, os textos são: 1) "A propósito da evolução da Geografia Industrial na França" de 1996 que caracteriza três abordagens da disciplina: descritiva, estrutural, política. 2) "Os efeitos geográficos das novas tecnologias: abordagem geral" de 1990 que considera os anos 1950-1960 e a crise dos anos 70; a emergência das novas tecnologias e da inovação nos anos 1970 e o êxito da $3^{\text {a }}$. Revolução industrial com surgimento das discussões sobre desenvolvimento endógeno e pequenas e médias Estudos Geográficos, Rio Claro, 15(1): 1-25, jan./jun. 2017 (ISSN 1678-698X)

http://www.periodicos.rc.biblioteca.unesp.br/index.php/estgeo 
Sposito $^{10}$ (2008). Renomado geógrafo da indústria, A. Fischer é conhecido dos brasileiros ${ }^{11}$.

Conforme Fischer (2008a, p. 17), a geografia industrial adquiriu autonomia, inclusive em relação à geografia econômica, após 1950 apresentando três abordagens: descritiva (até por volta de 1950); estrutural (anos 1960) e política (desde início dos anos 1980). As pesquisas da disciplina sempre estiveram vinculadas à função da indústria no ordenamento do território e no desenvolvimento regional; e, mais recentemente, às transformações geradas no interior da indústria pela inovação tecnológica e às modificações do sistema produtivo e do modelo de desenvolvimento, que conduziram atenção sobre as estratégias dos atores e sobre o relacionamento da atividade da indústria e seu ambiente.

De acordo com Fischer (2008a, p. 21), na contemporaneidade a geografia da indústria começa a enfatizar temas como: a estratégia dos atores; as Pequenas e Médias Empresas-Pequena e Médias Indústrias (PMEs-PMIs); as indústrias de alta tecnologia; a reconversão das regiões em crise; os novos espaços de atividades; as telecomunicações e as novas Tecnologias da Informação e da Comunicação - TICs; e os novos fatores de localização. Os trabalhos são realizados no contexto dos debates sobre políticas de ordenamento e de desenvolvimento e, nesse sentido, os meios inovadores tornaram-se interesse dos geógrafos.

Conforme Fischer (2008a, p. 21), no âmbito dos conceitos e teorias, a geografia industrial é caracterizada por: 1) influência dos pesquisadores anglosaxões, uma volta ao economicismo, uma economia que privilegiou o estudo dos sistemas produtivos e a organização funcional e espacial da indústria; e 2) retorno à dimensão local, não segmentado e compartimentado; um local integrante de todos os constituintes dos meios geográficos, onde estão as coletividades. Identifica-se, na primeira, inter-relações geográficas e econômicas que se apoiam na discussão da teoria da localização industrial. Na segunda, o foco é na análise do quadro regional, na tendência de concentração geográfica, nos movimentos de mão de obra, nos padrões de distribuição industrial, nas relações da indústria com a urbanização e na política governamental de desenvolvimento.

Com as modificações contemporâneas há uma ênfase na inovação como um processo que favorece o desenvolvimento econômico. Por isso, Fischer (2008b, p. 23) afirma que "a inovação e as novas tecnologias têm modificado o conteúdo da atividade industrial e também a organização espacial da indústria e a organização e a estruturação dos espaços geográficos".

empresas; além da indústria de alta tecnologia e dos novos espaços industriais. 3) "Zonas industriais e estratégias econômicas e espaciais" é um trabalho teórico voltado para geógrafos e urbanistas com as zonas industriais apresentadas em três abordagens. 4) "A empresa e o território" em que aborda o espaço geográfico, estruturado por um sistema de fluxos e redes relacionais de empresas. E, por fim, 5) "Estratégia de desenvolvimento das coletividades e estratégias industriais das firmas: reflexões a propósito da pertinência da escala local", que trata da relação entre desenvolvimento local e as PMEs e as estratégias dos atores - as coletividades, as empresas, o Estado.

${ }^{10}$ Os artigos de André Fischer foram organizados conjuntamente pelos brasileiros e também geógrafos Olga Lúcia Firkowski e Eliseu Sposito que objetivaram divulgar a produção dos últimos 40 anos, do professor Fischer. O livro foi lançado oficialmente no Brasil em 2009, quando ele veio ao país.

\footnotetext{
${ }^{11}$ André Fischer esteve no Brasil a convite do Programa de Pós-Graduação na UNESP, Faculdade de Ciências e Tecnologia, de Presidente Prudente (SP), para o período de 15 de julho a 31 de agosto de 1997. Ministrou palestras sobre "Planejamento Regional e Geografia da Indústria na Universidade Estadual de Maringá e Universidade Estadual de Londrina" (FAPESP, s.d).
}

Estudos Geográficos, Rio Claro, 15(1): 1-25, jan./jun. 2017 (ISSN 1678-698X)

http://www.periodicos.rc.biblioteca.unesp.br/index.php/estgeo 
No processo industrial, devido ao desenvolvimento da crise de 1970 e à corrida à inovação, a empresa precisou tomar decisões e definir estratégias econômicas; já que o comportamento da firma é objeto de análise da teoria da localização industrial. Conforme Fischer (2008b, p. 27), a empresa industrial é "um sistema dinâmico que sempre se ajusta às mudanças conjunturais ou cíclicas da economia, das técnicas, das estruturas sociais". Em conjunto, o papel da indústria mudou durante a Terceira Revolução Industrial. Apesar de mais qualificados, há uma diminuição dos empregos; as grandes empresas multiplicam as Pequenas e Médias Empresas (PMEs), pois estas são uma estrutura flexível e móvel que facilita a adoção de novas tecnologias; e as unidades técnicas especializadas praticam cada vez mais deslocalizações geográficas seletivas, para espaços mais baratos, de atividades mais banais.

Para explicar as divisões territoriais das atividades econômicas, conforme exigências de funcionamento das empresas e dos estabelecimentos, as novas tecnologias mudaram os fatores de localização. Atualmente, os gastos com transporte são fator secundário, se comparado ao acesso à pesquisa, à alta qualificação da mão de obra e à presença de vários serviços à empresa. $O$ desenvolvimento das indústrias de alta tecnologia modificou a mobilidade espacial das atividades industriais, pois consideradas footloose, fizeram com que as determinações de localização fossem menos importantes do que a lógica da organização interna das empresas. As mudanças da inovação tecnológica levam ao ajustamento dos métodos das empresas que precisam encarar a multiplicação de novos processos, novas máquinas e novos produtos, para serem competitivas. 0 desenvolvimento econômico é interpretado com base no progresso pela base; pelo recurso às PME-PMls; e pela corrida à inovação tecnológica (FISCHER, 2008b, p. 28).

O desenvolvimento pela base ocorreu pela ação das coletividades local e territorial objetivando assegurar a continuidade do crescimento, pois havia reduzido a ação econômica do Estado. O uso das PME-PMI tem papel essencial nas novas estratégias de três principais atores de desenvolvimento: empresas, coletividades territoriais, Estado. A corrida à inovação é essencial para as empresas conseguirem melhor posição concorrencial e ganho de produtividade. Esse processo de inovação fez aparecer: 1) estruturas internas nas empresas, com o desenvolvimento de função de Pesquisa e Desenvolvimento (P\&D), multiplicação de novos processos e produtos; 2) política de pesquisa da empresa para assegurar as transferências tecnológicas no conjunto da estrutura industrial e do território com a intervenção do poder público para sustentar e desenvolver a inovação; 3) multiplicação de novos espaços industriais, como parques científicos, tecnoparques, parques de inovação e tecnopolos ilustram a necessidade de oferecer às atividades de inovação, espaços propícios ao seu desenvolvimento.

A inovação tecnológica faz com que as indústrias de alta tecnologia gerem novos trabalhos e novos empregos. Há uma reorganização ou criação de novos mercados de trabalho das novas indústrias: mão de obra altamente qualificada sobre os planos científico e técnico, capaz de se adaptar, móvel. Assim, o trabalho e a divisão espacial do trabalho tornam-se elementos de diferenciação e da estruturação dos espaços geográficos. É com as indústrias de alta tecnologia que o espaço geográfico, por meio das localizações, torna-se um fator estratégico.

No período contemporâneo e com a evolução geral das tecnologias, o conhecimento tornou-se um input muito importante na sociedade atual. Esse Estudos Geográficos, Rio Claro, 15(1): 1-25, jan./jun. 2017 (ISSN 1678-698X) http://www.periodicos.rc.biblioteca.unesp.br/index.php/estgeo 
fenômeno - interpretado mais como as atitudes intelectuais que como único conhecimento - e a força de trabalho de alto nível de qualificação são bens decisivos para as empresas; a capacidade de acesso à informação científica e a conexão com redes científicas são fundamentais, sobretudo, para as PMEs, cuja possibilidade de investimentos em pesquisa é limitada. O tipo de mão de obra regional, o nível de qualificação da força de trabalho e o potencial regional de formação constituem variáveis afetam a localização das atividades industriais e da inovação (FISCHER, 2008b, p. 39).

Sobre a relação de localização entre tecnologia, inovação e atividade manufatureira há uma relevância aos espaços regionais e locais considerados como meios e os ambientes mais atrativos ou eficazes, a partir das possibilidades de sinergias e de parcerias e das redes de inovação. Como o estabelecimento industrial é sempre inscrito em um meio local, a criação de sinergias depende da cooperação estabelecida entre todos os atores do desenvolvimento local, públicos ou privados, institucionais ou não. A inovação industrial está cada vez mais ligada às políticas de dispersão assim como às políticas de transferência de tecnologia.

Qualquer que seja o tipo de meio local, a capacidade de desenvolver atividades de inovação é associada à capacidade de assegurar transferência de conhecimento e de tecnologia, a partir dos laboratórios das universidades, dos centros privados e públicos de pesquisas, das agências e dos escritórios de consulta. À escala regional, a capacidade de inovação e os efeitos de sinergia tornaram-se meios complexos em virtude da carga dos desequilíbrios surgidos da oposição entre espaços metropolitanos e regiões periféricas. Considerando o crescimento e o desenvolvimento como dependentes da capacidade regional de promover a inovação, deve-se acrescentar a importância às estratégias de parceria das empresas, à criação de redes de inovação e à criação de capacidades permanentes de transferir tecnologia; além das políticas que permitam às regiões frágeis se apoiarem nas redes de inovação das regiões fortes.

Existem múltiplas formas e tipos de inovação, assim como várias categorias de empresas inovadoras; variedade que é fator dos efeitos geográficos da inovação. Surgem novos ramos de atividade industrial e novos mercados, como a microeletrônica, as Tecnologias da Informação (Tls), a automatização flexível, os novos materiais, a biotecnologia, a engenharia médica, as tecnologias da energia. $A$ aplicação das tecnologias fundamentais é consagrada a alguns setores: indústrias de defesa; aeronáutica e aeroespacial; eletrônica; química; pesquisadesenvolvimento; indústria automotiva.

A distinção básica de inovação tecnológica é entre inovação de processo e inovação de produto. Os objetivos da inovação tecnológica, conforme tipologias são: adaptação, valorização, antecipação, radical, tipologias que influenciam locacionalmente (FISCHER, 2008b, p. 42). A difusão de inovação e a transferência de tecnologia se impõem como fundamentais porque têm influência direta sobre a localização das atividades econômicas. Esses processos são assegurados por quatro atores principais: as grandes empresas, os poderes públicos centrais, as universidades e grandes organismos institucionais de pesquisas, e coletividades locais (FISCHER, 2008b, p. 45).

$\mathrm{Na}$ difusão de inovação e na transferência de tecnologia, o papel das empresas é decisivo; manifesta-se pela criação de filiais especializadas e pela multiplicação de subcontratados especializados, dois elementos que representam, para a grande firma, uma forma de desenvolver e controlar novas tecnologias. A Estudos Geográficos, Rio Claro, 15(1): 1-25, jan./jun. 2017 (ISSN 1678-698X) http://www.periodicos.rc.biblioteca.unesp.br/index.php/estgeo 
ação do Estado constitui um complemento indispensável, e a atuação ocorre através de objetivos políticos, como: facilitar a difusão da informação científica e técnica no conjunto da estrutura industrial para evitar que as PMEs não sejam deixadas de fora da tecnologia e assegurar a difusão da informação científica e técnica sobre o conjunto do território nacional a todos, independentemente da localização geográfica. Em segundo lugar, a atuação do Estado se concretiza pela implantação de estruturas especializadas para a difusão da inovação, a transferência da tecnologia e o auxílio às empresas, através de várias agências regionais.

As empresas e os grandes organismos públicos de pesquisa são relevantes, em termos de difusão da inovação e da transferência de tecnologia, por acolherem pesquisadores das indústrias em seus laboratórios e pelos contratos de pesquisa com as empresas, atração exercida pela função de polo científico, a presença de bancos de dados, dentre outros. Por fim, as coletividades locais colaboram com a cooperação entre a municipalidade, os organismos e as associações profissionais, originando uma multiplicação de centros de pesquisa.

As exigências da inovação e das indústrias de alta tecnologia originam uma nova geração de espaços industriais, como várias denominações: parques de atividades, parques tecnológicos e tecnopolos; sendo uma estratégia de política territorial do Estado para reestruturar as velhas zonas industriais e minimizar os desequilíbrios regionais. Entende-se que esses objetos de estudo/análise e política econômica têm origem nos primeiros DI/polos de desenvolvimento, evoluindo de área/zona industrial a parques tecnológicos/tecnopolos. Fischer (2008c, p. 53) afirma que "zona industrial é uma grande área criada com apoio direto do Estado, expressão do planejamento das atividades econômicas e de um ordenamento espacial, portanto, um instrumento privilegiado de estratégias econômicas e espaciais"; é um equipamento que permite aprimorar os efeitos econômicos (rentabilidade dos investimentos) e responder às necessidades sociais (emprego).

Essas áreas industriais podem ser consideradas eficazes em termos de conteúdo e função regional, desde que: 1) o processo genético e a identidade do iniciador: zona concebida pelo Estado com presença da grande indústria; zona para uma operação regional concertada; zona ordenada pela municipalidade que espera a vinda das empresas; 2) a origem do investidor e a natureza da implantação: empresas locais (transferências centro-periferia da cidade), empresas exteriores (transferências ligadas ao processo de descentralização); e criação de atividades novas. O impacto é imediato sobre o grau de diversificação da zona e sobre a intensidade de suas ligações com o meio; 3) as características da mão de obra: relações entre as indústrias e o meio são diferentes dos empregos em maioria ocupados pela população local.

Entende-se que a atividade industrial é relevante na economia moderna e constitui objeto de estudo da geografia econômica; além disso, a expansão de áreas industriais e a difusão da inovação exige um ambiente científico-técnico-culturalinstitucional que resulte das combinações entre múltiplas intervenções.

\section{ANÁLISE E TIPOLOGIAS DE DISTRITOS INDUSTRIAIS}

A professora A. Markusen já é conhecida dos acadêmicos brasileiros. É autora de vários livros e artigos que tratam de economia regional e urbana, desenvolvimento, indústria militar e conteúdos relacionados.

Estudos Geográficos, Rio Claro, 15(1): 1-25, jan./jun. 2017 (ISSN 1678—698X)

http://www.periodicos.rc.biblioteca.unesp.br/index.php/estgeo 
A autora ${ }^{12}$ realiza um estudo de indicação metodológica sobre áreas industriais, indicando três modelos alternativos, com maior poder de atração e manutenção de investimento - "sticky places in slippery space" (áreas atrativas em espaços fluidos). Além da aglomeração de pequenas empresas inovadoras, estruturadas em uma organização de cooperação na esfera e direção regionais (NDIs da Terceira Itália), a autora defende a existência de outros três tipos de DIs: centro-radial; plataforma satélite; e ancorado pelo Estado - em países avançados ou em desenvolvimento recente, como os Estados Unidos, Japão, Brasil e Coréia do Sul; como experiências que mostram a força dos governos e de instituições multinacionais no arranjo de Dls.

Para Markusen ${ }^{13}$ (1995, p. 9), um mundo em que os sistemas de comunicação e mobilidade internacional das corporações estão mais acentuados; é curioso; porque certos lugares conseguem sustentar a atratividade para o capital e o trabalho. O problema é maior em cidades avançadas onde os níveis salariais e padrões de vida são mais elevados do que países incluídos atualmente aos circuitos mais importantes da economia. Os espaços de produção nesses países tornaram-se mais escorregadios, já que há facilidade de (re)localização de plantas produtivas em regiões de menor custo; e a delimitação espacial da produção tem se tornado mais fluida nas economias centrais.

Ela parte de métodos indutivos, procurando exceções à regra geral e analisando a estrutura e o funcionamento das áreas com maior poder de atração e de manutenção de investimentos. Nesse sentido, um tipo de pesquisa extensiva é o da literatura sobre "especialização flexível ou Novos Distritos Industriais (NDIs)", baseado na expansão das indústrias maduras, na região da Emília-Romagna, Itália.

Conforme Markusen (1995, p. 10), os NDls devem sua capacidade de atração e de retenção de investimentos às características das pequenas empresas, articuladas no interior de um sistema de cooperação regional, o que dá capacidade

\footnotetext{
12 A professora Ann Markusen é especialista em desenvolvimento econômico (escala estadual e local), analisando as maneiras que as indústrias e as formas de ocupação possibilitam a criação de um bom trabalho. Dentre suas publicações, destacam-se livros, monografias e artigos, como: "Defining the cultural economy, Economic Development Quarterly" (2007); "Urban development and the politics of a creative class: evidence from a study of artists, Environment and Planning" (2006); "The artistic dividend: urban artistic specialization and economic development implications, Urban Studies" (2006); "Silicon Landscapes" (1985) com Peter Hall (ed.) e o artigo "áreas de atração de investimentos em um espaço econômico cambiante: uma tipologia de distritos industriais" - 1995 (traduzido para o português pela revista Nova Economia). Inclui a discussão de incentivos fiscais (Reining in the Competition for Capital, 2007), a conversão industrial militar (Arming the Future: a Defense Industry for the 20th Century, 1999; Dismantling the Cold War Economy, 1992; The Rise of the Gunbelt, 1991), a alta tecnologia (high tech America, 1985), cidades do boom energético e das finanças públicas estadual/local. Nos últimos anos, suas consultorias e pesquisas concentraram-se em organizações artísticas e placemaking criativo (Mais nformações, http://annmarkusen.com/).
}

13 Ann Markusen é reconhecida dos acadêmicos brasileiros, esteve no Brasil de março a abril de 2008 , no
"Programa Cátedras Instituto de Estudos Avançados Transdisciplinares - IEAT/Fundação de Desenvolvimento da
Pesquisa - FUNDEP", área do conhecimento "Humanidades, Letras e Artes"; a convite do grupo de
pesquisadores do CEDEPLAR/FACE/UFMG (UFMG/IEAT, 2008). Ela realizou duas conferências: a primeira foi
em 28 de março, intitulada Artes e indústrias culturais no desenvolvimento regional. O objetivo foi analisar as
transformações na estrutura da economia, com o aumento da força e da relevância das atividades artísticas e
culturais; investigar, de maneira comparativa, a atribuição dessas atividades na geração de emprego e renda,
enfatizando um grupo de grandes cidades selecionadas dos EUA e da Europa, fundamentando em linhas
teóricas e metodológicas para discussão do contexto brasileiro. A segunda, Artistas como empresários e ativos
comunitários, ocorreu no dia 16 de abril e teve como propósito analisar a importância do arranjo empresarial no
avanço das atividades artísticas e culturais - os recursos artísticos e culturais de uma comunidade e sua
influência no desenvolvimento dessas atividades; e, por fim, as diversas maneiras de estimular o
desenvolvimento dessas atividades. Começou a trabalhar com a perspectiva cultura no âmbito do
desenvolvimento regional há alguns anos (UFMG/IEAT, 2008). Estudos Geográficos, Rio Claro, 15(1): 1-25, jan./jun. 2017 (ISSN 1678-698X)

http://www.periodicos.rc.biblioteca.unesp.br/index.php/estgeo 
de adaptação e crescimento, apesar das tendências globalizantes. Porém Markusen (1996, p. 11) desenvolveu sua pesquisa sobre três modelos alternativos (stick places) de maneira semelhante à utilizada na pesquisa sobre os NDIs. Seu estudo considerou a escala metropolitana e as áreas que tiveram melhor desempenho econômico em relação à média.

Conforme Markusen (op. cit.), a pesquisa teve a finalidade de "determinar em que medida o modelo tradicional de NDIs poderia explicar a durabilidade e 0 florescimento das economias regionais nos EUA, Japão, Coreia e no Brasil como na Terceira Itália". Ela afirma que poucas tentativas foram feitas para determinar se as aglomerações existentes são especializações flexíveis ou se as maiores indústrias são pós-fordistas.

Nos EUA, Japão, Coreia do Sul e no Brasil, os diversos Dls, mais maduros ou mais recentes, exibiram capacidade para resistir ao efeito de nivelamento de acelerada integração ao mercado mundial e na busca global por rentabilidade, atributos da crescente fluidez do espaço econômico em escala internacional. A autora identificou que a maioria desses enclaves não correspondia às características do NDI de especialização flexível.

Sua pesquisa identificou três padrões alternativos, com método envolvendo dois estágios:

Primeiro, pesquisou o crescimento metropolitano desde 1970 para cada um dos quatro países (EUA, Japão, Coreia do Sul e Brasil), identificando o universo daqueles que apresentaram taxas de crescimento significativamente mais elevadas do que a média nacional. Segundo, escolheu um subconjunto de casos para um estudo maior, baseado em dados desagregados da estrutura industrial e a opinião de especialistas na organização industrial. Para cada país foi selecionado, pelo menos, um caso, conforme perfil de NDI e três a cinco para outros, cujas estruturas industrial e organizacional pareceu ser bastante diferente. Realizou entrevista com empresários, associações comerciais, sindicatos e observadores da economia regional incorporando a literatura sobre estudos de empresas e entrevistas corporativas.

Investigou as características específicas na formulação tradicional sobre os NDls: distribuição do tamanho da firma, grau de desintegração vertical, redes entre as empresas distritais, estruturas de governança distritais, capacidades inovadoras, organização da produção; e explorou número de atributos geralmente não incorporado nos estudos:

Primeiro, foi examinado o papel do estado no nível nacional e regional/local como formulador de lei, produtor e consumidor de bens e serviços e como financiador de inovação, bem como a consequência dessa atuação para a distribuição e a fixação de emprego dentro e entre regiões.

Segundo, examinou-se o papel das grandes firmas, especialmente aquelas com poder de mercado interno e externo, em aglomerações em distritos e em redes não locais que se estendem através de espaço nacional e internacional.

Terceiro, observou-se o envolvimento das firmas em redes de negócios (networks) locais ou de caráter nacional ou internacional.

Quarto, uma vez que a rentabilidade varia durante o curso de amadurecimento de qualquer indústria e em função das formas de mudanças de competição, das estruturas organizacionais, das

Estudos Geográficos, Rio Claro, 15(1): 1-25, jan./jun. 2017 (ISSN 1678-698X)

http://www.periodicos.rc.biblioteca.unesp.br/index.php/estgeo 
características ocupacionais e das tendências locacionais, pesquisou-se, em cada distrito, a dinâmica de desenvolvimento a longo prazo das principais indústrias e de suas respectivas firmas, visando determinar a sua resistência/vulnerabilidade à decadência.

Em quinto lugar, buscou-se determinar, para períodos mais longos, o potencial dinâmico de cada região, incluindo a trajetória provável e a competitividade esperada do agrupamento industrial existente, bem como a sua capacidade de variedade de novos setores, sem conexões anteriores com os negócios locais.

Finalmente, buscou relações entre o arcabouço e a atuação dos distritos e certos indicadores de bem-estar social, como as taxas de crescimento do emprego ao longo do tempo, estabilidade cíclica, níveis de renda, lucro e distribuição de riqueza, presença sindical e política diversa. As implicações sociais de cada tipo de cada tipo de área de atração é uma tarefa complexa e raramente realizada. Estudiosos dos NDIs normalmente ressaltam a provisão de bons empregos e sua estabilidade e dinamismo de longo prazo (MARKUSEN, 1996, p. 13).

Para Markusen (1995), um pólo ou um distrito industrial de sucesso deve cumprir os seguintes requisitos:

Obtenção, na região, de crescimento na média ou acima da média para o conjunto das áreas pesquisadas; capacidade local de evitar falências e perdas de postos de trabalho decorrentes dos efeitos das oscilações de curto e médio prazos - ciclos de negócios ou de gasto público; oferta de bons empregos, contenção das tendências à segmentação salarial e prevenção de excessiva concentração da renda e da propriedade; livre organização dos trabalhadores e sua participação nos processos decisórios das empresas; incentivo à participação e à contestação política em âmbito regional (MARKUSEN, 1996, p. 14).

Ela define Distrito Industrial como "área espacialmente delimitada, com uma nova orientação de atividade econômica de exportação e especialização definida, seja relacionada à base de recursos naturais ou a certos tipos de indústria ou serviços" (MARKUSEN, 1995, p. 14). Em sua proposta de tipologia e classificação apresenta quatro tipos de espaços industriais diferentes (MARKUSEN, 1995, p. 15). O NDI marshalliano (variante italiana); NDI centro-radial (hub and spoke); NDI plataforma industrial satélite; e NDI suportado pelo Estado (state-centered).

O NDI Marshalliano, e sua variedade recente italiana, baseiam-se em uma região com estrutura de negócios composta de pequenas firmas com origem local que fazem investimento e decidem a produção local. Economias de escala têm pequena importância, o que restringe o porte dos negócios. A cooperação entre firmas de fora do distrito é praticamente inexistente; e o conteúdo e a característica do mercado de trabalho local são muito flexíveis.

O NDI centro-radial refere-se a regiões com determinada quantidade de "empreendimentos ou de unidades industriais mais relevantes que operam como firmas-chave ou eixos de economia regional, congregando em torno de si, fornecedores e outras atividades relacionadas". Ressalta-se a cidade de Toyota, no Japão, e São José dos Campos, no Brasil. Uma única grande empresa compra de

Estudos Geográficos, Rio Claro, 15(1): 1-25, jan./jun. 2017 (ISSN 1678—698X)

http://www.periodicos.rc.biblioteca.unesp.br/index.php/estgeo 
fornecedores locais ou externos, e vende para mercados constituídos por grandes compradores ou para um grande número de pequenos consumidores individuais.

O dinamismo das economias regionais com esse formato associa-se à posição das suas principais firmas ou unidades industriais em seus respectivos mercados nacionais ou internacionais, o que subordina outros negócios locais à sua sorte. Esses distritos podem exibir tanto uma teia mais firme de ligações quanto um caráter mais nuclear.

O NDI Plataforma Satélite é normalmente organizado longe dos "grandes centros urbanos por governos nacionais ou estaduais". Justifica-se pelo incentivo ao desenvolvimento de regiões distantes e pela tentativa de diminuição dos custos de negócios, que não têm de enfrentar altos salários, alugueis e impostos das maiores concentrações urbanas. As atividades desenvolvidas nessas plataformas podem variar desde simples rotinas de montagem (low-end cases) até pesquisas relativamente sofisticadas (high-end cases).

Nesse Distrito Industrial, a característica crucial é a completa inexistência de relações ou transações no interior do distrito e a sua exclusiva tendência para a sede ou para outras subsidiárias da mesma corporação, incluindo o intercâmbio pessoal. Esses distritos são encontrados em quase todos os países. Ressalta-se a plataforma high-end nos EUA e o Research Triangle Park, conjunto de centros de pesquisa independentes entre si e ligados a grandes corporações multinacionais. Um caso low-end é o de Elkart, no estado da Indiana, onde o fator de atração foram os salários baixos. No Brasil, a autora cita a expansão, financiada pelo poder público, da Zona Franca de Manaus.

Outro tipo de área de atração é o NDI centrado no Estado em que a "estrutura dos negócios fica em torno de alguma entidade pública ou não lucrativa, seja uma base militar, uma universidade, um centro de pesquisa ou laboratório ligado ao setor bélico". Aproxima-se de um distrito Centro-Radial e da Plataforma Satélite. Nos EUA, academias e bases militares ou centros de pesquisas bélicas explicam o crescimento de cidades como Santa Fe e San Diego. As universidades públicas explicam a importância de algumas cidades, como Campinas e São José dos Campos, no Brasil; esta última ganhou importância devido ao complexo aéreoespacial do governo federal.

Um distrito autêntico pode ser representado por um ou pela combinação de dois ou mais tipos e, no decorrer do tempo, pode mudar de um tipo para outro. Conforme Markusen (1995, p. 34), áreas de atração são o produto complexo de várias forças, sejam estratégias empresariais, estruturas industriais, prioridades de governos, ciclos de lucros, política regional e nacional. O sucesso não pode ser compreendido na escala meramente local, pois incluem as empresas presentes, os trabalhadores, universidades ou órgãos de governo que participam de um acervo de conexões, competitivas e cooperativas, que ultrapassam as fronteiras do distrito e possibilitam seu sucesso.

Segundo markusen (op. cit., p. 35), essa abordagem investigativa é aplicável à política de desenvolvimento econômico em níveis regional e nacional. No nível regional, os planejadores econômicos seriam melhor orientados para avaliar suas estruturas distritais existentes com precisão e conceber estratégia em torno deles, ao invés de se comprometerem com estratégia de moda de redes de pequenas empresas na região. Melhorar as relações de cooperação e construção de redes que chegam de fora da região pode ser mais produtivo para algumas localidades.

Estudos Geográficos, Rio Claro, 15(1): 1-25, jan./jun. 2017 (ISSN 1678—698X) http://www.periodicos.rc.biblioteca.unesp.br/index.php/estgeo 
Em nível nacional, as estratégias para melhorar a concorrência regional e a taxa de crescimento são: determinar quantos distritos de cada tipo tenderiam a se formar na economia nacional; desenvolver estratégia para estabilizar distritos existentes e canalizar novos para zonas de menor dinamismo econômico; proibir uso de fundo público para subsidiar competição entre regiões; monitorar e, se necessário, alterar as políticas nacionais com grande repercussão regional - novos regimes comerciais; iniciativas de política macroeconômica; e normas ambientais internacionais.

Discutiu-se estudos teórico-metodológicos de geografia econômica que se inserem no contexto geral da globalização e da Terceira Revolução Industrial sob emergência de outro sistema produtivo e da ênfase na inovação. No Brasil, apresentam-se alguns debates relacionados à disciplina no contexto das abordagens atuais.

Após 1990, cita-se "Análise da organização espacial da indústria nordestina através de uma tipologia de centros industriais" (1991), de Miguel Ângelo Campos Ribeiro e Roberto Schmidt Almeida; "Que fazer da geografia econômica neste final do século?" (1994), de C. A. G. Egler; "Padrões tecnológicos e reorganização espacial no final do milênio" (1995), de Roberto Schmidt - que aborda o tema da tecnologia e suas consequências no espaço e as ações do Estado; "O Sistema Nacional de Ciência, Tecnologia e a promoção tecnológica regional e local no Brasil" (2012), de F. A. Veloso Filho; R. B. Júnior; e C. D. P. Sil va -que inserem o tema da inovação a partir da concepção de sistemas de inovação localizados do Brasil, considerando a relevância desse conceito na formulação de política econômica para regiões.

No âmbito institucional, as estratégias para inovação no Brasil iniciam a partir da década de 1980, com a criação do primeiro programa de Parque Tecnológico em São Carlos (SP), 1984, e a criação de organismos federais para o desenvolvimento do Sistema Nacional de Ciência e Tecnologia - SNCT. Algumas ações para o desenvolvimento tratam da política de Arranjos Produtivos Locais (APLs), as aglomerações produtivas, da década de 1990; e do Programa Nacional de Apoio a Incubadoras de Empresas e Parques Tecnológicos (PNI), reinstituído em 2009, para implantação e consolidação de ambientes de inovação brasileiros.

No nível acadêmico, o grupo de pesquisadores da RedeSist (http://www.redesist.ie.ufrj.br/), da Universidade Federal do Rio de Janeiro, trata de APLs como instrumento de desenvolvimento; destacando-se os trabalhos dos geógrafos Cleonice Alexandre Le Bourlegat em "Políticas públicas e mapeamento de APLs em Mato Grosso do Sul" (2010); Dean Lee Hansen em "Análise das políticas de apoio para Arranjos Produtivos Locais no estado de Sergipe" (2010); e Francisco de Assis Veloso Filho em "Identificação e análise de políticas para Arranjos Produtivos Locais no estado do Piauí" (2010). Além do grupo de pesquisadores do Cedeplar (http://www.cedeplar.ufmg.br/), da Universidade de Minas Gerais tratando do desenvolvimento regional e de estudos sobre parques tecnológicos. Com a constatação da importância da inovação na sociedade, consolida-se o tema de C, T\&I e, assim, do Sistema Nacional de Ciência, Tecnológica e Inovação - SNTCI para a promoção econômica regional e local no Brasil, tornando-se discussão de diversas disciplinas.

Com a constatação da importância do tema inovação na sociedade e nas ciências, a Geografia mundial tem tratado da dimensão espacial das atividades de inovação e divulgado essa abordagem na disciplina, a partir da realização de Estudos Geográficos, Rio Claro, 15(1): 1-25, jan./jun. 2017 (ISSN 1678—698X) http://www.periodicos.rc.biblioteca.unesp.br/index.php/estgeo 
eventos internacionais. A Geografia Econômica mundial tem levantado questões contemporâneas que podem ser identificadas nos temas das conferências ocorridas desde fim do século XX, com a participação de especialistas de várias áreas do conhecimento, e organizada por grupos de pesquisadores que tratam desse subramo e da abordagem da C,T\&l.

Vale ressaltar o evento Global Conference on Economic Geography, ocorrendo desde o ano de 2000, sendo o último organizado pela School of geography and the environment, da Universidade de Oxford, na Inglaterra - 4a . Conferência Mundial de Geografia Econômica, em 2015; e a rede de pesquisadores de laboratórios franceses European Localized Innovation Observatory - EuroLIO (https://eurolio.univ-st-etienne.fr/content/about-us?language=en) que preparou junto com o grupo de pesquisadores do LEREPS (http://lereps.sciencespo-toulouse.fr/), da Universidade Sciences-Po Toulouse, o evento Geography of Innovation Conference - 3‥ Conferência de Geografia da Inovação, em 2016.

\section{CONSIDERAÇÕES FINAIS}

Objetivando elaborar um trabalho que mostre uma visão geral da geografia econômica, especificamente do estudo da indústria na contemporaneidade, utilizouse bibliografias de autores estrangeiros como André Fischer, Georges Benko e Ann Markusen, que tratam do tema da inovação localizada. As mesmas foram selecionadas em virtude de constituírem literatura consolidada na abordagem da inovação e de áreas planejadas para atividades econômicas inovadoras. Além disso, se apresentou estudos de geografia econômica que tratam da promoção econômica para o desenvolvimento, considerando os APLs e os ambientes de inovação no âmbito do Brasil; e se identificou tendências mais atuais nesse ramo disciplinar.

Entende-se que há uma renovação na geografia após 1970 no mundo, que se desdobra para os estudos geográficos em outros países, como o Brasil. As novas conjunturas econômico-social e científica conduziram a geografia econômica à revisão das modalidades e temáticas. As abordagens gerais - neoschumpeteriana, regulacionista, californiana - contribuem para novas teorias, conceitos e métodos que influenciam nos temas de pesquisa geográfica como a localização industrial, a concentração de atividades econômicas e os novos espaços econômicos (PME; indústrias de alta tecnologia; e metrópoles que disponibilizam variedade de serviços) no contexto da inovação e da emergência do sistema produtivo flexível, conforme Benko (1996).

Conforme Fischer (2008), a geografia industrial fundamenta-se na abordagem economicista e na teoria da localização industrial; e na abordagem dos estudos do quadro regional. A fase contemporânea denominada de tempos de confirmação inclui temas como estratégia dos atores; as PME-PMls; indústria de alta tecnologia; novos fatores de localização; novas tecnologias da informação e da tecnologia. A inovação é uma das estratégias de desenvolvimento, além do progresso pela base (desenvolvimento endógeno) e do surgimento das PME-PMI. As exigências da inovação e novas tecnologias originam diferentes espaços industriais como novos Dls, parques tecnológicos e tecnopolos.

Benko (1996) analisa e classifica esses meios inovadores em uma pesquisa da indústria e, fundamentado na abordagem regulacionista, trata de aglomerações produtivas contemporâneas no âmbito regional. Analisa a abertura dos sistemas locais para seu milieu e propõe quatro tipos de sistemas territoriais em meios Estudos Geográficos, Rio Claro, 15(1): 1-25, jan./jun. 2017 (ISSN 1678—698X) http://www.periodicos.rc.biblioteca.unesp.br/index.php/estgeo 
inovadores: 1) sistemas territoriais dinâmicos; 2) contextos locais de meios que não são dinâmicos; 3) contextos locais que não são inovadores, nem dinâmicos; e 4) o sistema de dinâmica mantida de maneira exógena que inclui Paris e llê-de-France e, portanto, a Cidade Científica (Ilê-de-France-Sud), que causa impacto econômico positivo na região.

Markusen (1995) apresenta quatro tipos de Dls, dos quais propõe três tipologias de alcances regional/nacional - centro-radial; plataforma industrial satélite; ancorado pelo Estado; além do DI marshalliano (e sua variante italiana), em economias regionais. Seu trabalho considera a capacidade dessas áreas em atrair e reter capital em um "sticky places in slippery space" - áreas atrativas em espaços fluidos. Contrário à ênfase nas pequenas empresas, de especialização flexível e cooperação local, a autora mostra a ação dos governos e multinacionais em outros DIs. Realiza uma pesquisa que parte dos NDIs, identificando que a maioria dos DIs que resistiram à crescente fluidez do espaço econômico em escala internacional não possuía características flexíveis. Além disso, um DI real pode ser a combinação de um ou mais tipos que, no decorrer do tempo, pode mudar.

No âmbito do desenvolvimento regional, dois aspectos passaram a ser fundamentais, atualmente: formas organizacionais, baseadas na proximidade local, como clusters, arranjos locais de empresas, parques tecnológicos/tecnopolos e Dls; e o ambiente onde essas organizações estão inseridas. O novo sistema produtivo, marcado por mudanças na estrutura de mercado, mão de obra e fatores e técnicas de produção, levou ao conceito de flexibilidade, produção flexível ou acumulação flexível, em que os tecnopolos aparecem como sistemas produtivos locais que poderão tornar-se espaços estimuladores da acumulação flexível, conforme os trabalhos dos geógrafos franceses. Para o desenvolvimento dos sistemas regionais/locais de inovação, o Estado, as empresas, as instituições de ensino e pesquisa, e as coletividades locais precisam atuar em interação.

Seja parque ou pólo tecnológico, tecnopólo ou parque de atividades, essas denominações são originárias das concepções de Distrito Industrial de Alfred Marshall e de Pólo de Desenvolvimento de François Perroux - uma das grandes preocupações da geografia, pois são áreas para atração de indústrias que influenciarão na organização do espaço devido à distribuição de atividades econômicas. No caso das áreas industriais recentes, há a inserção do fenômeno de inovação. Por isso, são gerações de áreas industriais, atualmente com empresas inovadoras (indústrias de ponta).

G. Benko define o novo tipo de DI de tecnopolo, que é um centro marcado por atividades industriais de alta tecnologia sendo fundamental na transferência de tecnologia; ou um aglomerado de empresas inovadoras, dinâmicas, motrizes em que o investimento nas empresas mais rentáveis (em renda per capita e emprego) tem efeitos relevantes em toda a economia regional. André Fischer define zona industrial como instrumento privilegiado de certas estratégias econômicas e espaciais. Criada com apoio direto do Estado é expressão da planificação das atividades econômicas e de um ordenamento espacial pensado na escala interurbana (inter-regional). Já A. Markusen, define esses espaços, os Dls, como uma área espacialmente delimitada com uma nova orientação de atividade econômica de exportação e especialização definida, seja relacionada à base de recursos naturais ou a certos tipos de indústria ou serviço.

O estudo da indústria é um tema consagrado na geografia e continua objeto de pesquisas dos geógrafos e de outros profissionais que estão no ramo da Estudos Geográficos, Rio Claro, 15(1): 1-25, jan./jun. 2017 (ISSN 1678-698X) http://www.periodicos.rc.biblioteca.unesp.br/index.php/estgeo 
geografia econômica. No Brasil, após 1990, no nível acadêmico continuam as discussões sobre a indústria em âmbito regional e os grupos de pesquisas inserem a abordagem da inovação, inclusive em termos de aglomerações produtivas inovadoras; também nesse período avançam debates sobre o tema tecnologia e suas consequências no espaço, no contexto das ações do Estado. De forma aplicada, os estudos geográficos tratam de política de promoção para desenvolvimentos regional/local, através dos APLs; e das Incubadoras de Empresas e dos Parques Tecnológicos (PNI), para consolidação do SNCTI.

Com a constatação da relevância da inovação na sociedade e nas ciências, a Geografia mundial tem abordado a dimensão espacial das atividades de inovação no âmbito econômico, a partir da realização de eventos internacionais, que refletem as questões contemporâneas ocorridas desde fim do século $X X\left(1^{\circ}\right.$ evento de Geografia Econômica foi no ano 2000), com a participação de especialistas de várias áreas do conhecimento, e organizada por redes/grupos de pesquisadores que tratam desse sub-ramo e da abordagem da C,T\&I no mundo, como a EuroLIO (França).

Por fim, entende-se que o estudo da geografia econômica/industrial baseiase em classificações, definições, formulação de hipóteses, dedução de teorias, análises quantitativas de atividades econômicas e mensuração do impacto na região. Como setor moderno e que transforma a realidade econômica, o incentivo à expansão da atividade industrial mediante áreas industriais e o reconhecimento da inovação como motor do desenvolvimento (presente também nas micro e pequenas indústrias) são objetos de pesquisa atualmente. Assim, espera-se contribuir com a ciência geográfica e, nesse sentido, com os debates contemporâneos da geografia econômica que buscam explicar a realidade geográfica dos países e regiões.

\section{REFERÊNCIAS}

ALMEIDA, Roberto Schmidt. Padrões tecnológicos e reorganização espacial no final do milênio. Revista Brasileira de Geografia, ano, v. 57, n. 3, p. 5-19, jul/set, 1995.

BENKO, Georges. Economia, espaço e globalização na aurora do século XXI. Tradução Antônio de Pádua Danesi. São Paulo: Hucitec, 1996. 266 p.

BENKO, Georges. La géographie économique: um siècle d'histoire (2008). Annales de géographie, 2008, n. 664, p. 23-49.

BENKO, Georges. Economia e urbana regional na virada do século. In: RIBEIRO, M. T.; MILANI, C. R. S. (org.). Compreendendo a complexidade socioespacial contemporânea: o território... Salvador: EDUFBA, 2009. 312 P.

BREITBACH, A. Indústria, ordenamento do território e transportes - a contribuição de André Fischer. Confins, n. 5, 2009. Postado em 20 mar. de 2009. Disponível em: <https://confins.revues.org/5630?lang=pt>. Acesso em: 25 out. 2012.

CLAVAL, P. Georges Benko (1953-2009). European Spatial Research and Policy, v. 18, n. 2, p. 5-7, nov. 2011. Disponível em:

<http://www.degruyter.com/view/j/esrp.2011.18.issue-2/v10105-011-0007-y/v10105011-0007-y.xml>. Acesso em: 20 fev. 2016.

Estudos Geográficos, Rio Claro, 15(1): 1-25, jan./jun. 2017 (ISSN 1678-698X)

http://www.periodicos.rc.biblioteca.unesp.br/index.php/estgeo 
CLAVAL, P. Georges Benko. Geografia econômica e economia. Geotextos, v. 1, n.1, 2005, p. 11-27.

CLAVAL, P. Georges Benko. A diversidade das geografias econômicas.

Geographia, v. 14, n. 2. 2012. p. 7-20.

CARVALHO, D. R. P; VELOSO FILHO, F. A. Geografia Econômica: origem, perspectivas e temas relevantes. Caderno de geografia, v. 27, n.50, 2017, p. 573588.

EGLER, C. A. Que fazer com a geografia econômica neste final de século? Textos Laget, 1995, p. 5-12.

FAPESP - Fundação de Amparo à Pesquisa do Estado de São Paulo. André Fischer, Universite Paris I - França. Biblioteca virtual/Centro de Documentação e Informação da Fundação de Amparo à Pesquisa do Estado de São Paulo.

Disponível em: < http://www.bv.fapesp.br/pt/auxilios/49902/andre-fischer-universiteparis-i-franca/>. Acesso em: 20 jan. 2016.

FISCHER, André. A propósito da evolução da Geografia Industrial da França. In: FIRKOWSKI, Olga Lúcia; SPOSITO, Eliseu Savério (org.). Indústria, ordenamento do território e transportes: a contribuição de André Fischer. São Paulo: expressão popular, 2008a, p. 17-22. Tradução de: A propôs de l'evolution de la Géographie Industrielle em France, 1996.

FISCHER, André. Os efeitos geográficos das novas tecnologias: abordagem geral. In: FIRKOWSKI, Olga Lúcia; SPOSITO, Eliseu Savério (org.). Indústria, ordenamento do território e transportes: a contribuição de André Fischer. São Paulo: expressão popular, 2008b, p. 23-52. Tradução de: Les effets géographiques des technilogies nouvelles. Approche génerale, 1990.

FISCHER, André. Zonas industriais e estratégias econômicas e espaciais. In: FIRKOWSKI, Olga Lúcia; SPOSITO, Eliseu Savério (org.). Indústria, ordenamento do território e transportes: a contribuição de André Fischer. São Paulo: expressão popular, 2008c, p. 53-60. Traduzido de: Zones industrielles et stratégies économiques et spatiales, 1981.

FISCHER, André. A empresa e o território. In: FIRKOWSKI, Olga Lúcia; SPOSITO, Eliseu Savério (org.). Indústria, ordenamento do território e transportes: a contribuição de André Fischer. São Paulo: expressão popular, 2008d, p. 61-68. Tradução de: L'entreprise et le territoire, 1996

FISCHER, André. Estratégia de desenvolvimento das coletividades e estratégias industriais das firmas: reflexões a propósito da pertinência da escala local. In: FIRKOWSKI, Olga Lúcia; SPOSITO, Eliseu Savério (org.). Indústria, ordenamento do território e transportes: a contribuição de André Fischer. São Paulo: expressão popular, 2008e, p. 69-76. Tradução de: Stratégies de développemente des collectivités et stratégies industrielles des firmes: réflexions à propôs de la pertinence de l'echelle locale, 1992.

Estudos Geográficos, Rio Claro, 15(1): 1-25, jan./jun. 2017 (ISSN 1678—698X) http://www.periodicos.rc.biblioteca.unesp.br/index.php/estgeo 
HANSEN, D. L. et. al. Análise das políticas de apoio para Arranjos Produtivos Locais no estado de Sergipe. In: APOLINÁRIO, V.; SILVA, M. L. (Org.). Políticas para Arranjos Produtivos Locais: análise em estados do Nordeste e Amazônia Legal. RN: EDURFN, 2010, p. 367-388.

LE-BOURLEGAT, C. A; OLIVEIRA, M. A. C. Políticas públicas e mapeamento de APLS em Mato Grosso do Sul. In: CAMPOS, R.R; STALLIVIERI, F.; VARGAS, M. A.; MATOS, M. (Org.). Políticas estaduais para Arranjos Produtivos Locais no Sul, Sudeste e Centro-oeste do Brasil. Rio de Janeiro: e-pepers, 2010, p. 291-333.

MARKUSEN, Ann. Áreas de atração de investimentos em um espaço econômico cambiante: uma tipologia de distritos industriais. Nova Economia, v. 5, n. 2, 1995. Cedeplar. p. 9-44.

MÉNDEZ, R. Fallece un miembro del Comité Cientifico de IIRR, el Dr. Georges Benko. Journal of regional research investigaciones regionales. Seção noticias y novedad. Postado em 23 de julho de 2009. Disponível em: < http://www.investigacionesregionales.org/Novedades-448-new>. Acesso em: 17 jan. 2016.

RIBEIRO, M. A. C. ALMEIDA, R. S. Análise da organização espacial da indústria nordestina através de uma tipologia de centros industriais. Revista Brasileira de Geografia, Rio de Janeiro, ano 53, n. 2, p. 5-31, abr/jun 1991.

UFMG - UNIVERSIDADE FEDERAL DE MINAS GERAIS. Ann Markusen analisa a importância da cultura para o desenvolvimento regional. Belo Horizonte. Agência de notícias UFMG. Postado em 28 de março de 2008. Disponível em: <https://www.ufmg.br/online/arquivos/008111.shtml>. Acesso em: 23 set. de 2013. . Instituto de Estudos Avançados Transdisciplinares - IEAT. Ann Markusen Universidade de Minnesota. Cátedra IEAT/Fundação de Desenvolvimento da Pesquisa - FUNDEP: Humanidades, Letras e Artes. 2008. Disponível em: < https://www.ufmg.br/ieat/2011/09/ann-markusen/>. Acesso em: 23 jun. 2014.

VELOSO FILHO, F. A. et. al. Identificação e análise de políticas para Arranjos Produtivos Locais no estado do Piauí. In: APOLINÁRIO, V.; SILVA, M. L. (Org.). Políticas para Arranjos Produtivos Locais: análise em estados do Nordeste e Amazônia Legal. Natal, RN: EDUFRN, 2010, p. 315-331.

VELOSO FILHO, F. A; SANTOS JÚNIOR, R. B.; SILVA, C. D. P. O sistema nacional de ciência, tecnologia e inovação e a promoção tecnológica regional e local no Brasil. Cadernos de Pesquisa em Ciência Política, Teresina, PI, ano 1, n. 1, 52 p, jul./dez. 2012. 